\title{
A VULNERABILIDADE DA MULHER IDOSA EM RELAÇÃO À AIDS
}

\author{
Carla M arins SILVA a, Fernanda M aria do Valle M artins LOPES ${ }^{b}$, Octavio M uniz da Costa VARGEN Sc
}

\section{RESUMO}

T rata-se de revisão sistemática da literatura que abrange o período de 1994 a 2009, cujo objetivo foi discutir a vulnerabilidade da mulher idosa em relação às D oenças Sexual mente T ransmissíveis e Síndrome da Imunodeficiência A dquirida (Aids). Foi realizada a busca nas bases: Biblioteca Virtual em Saúde, Scientific E letronic L ibrary O nline (SciE LO ), Literatura L atino-A mericana e do Caribe em Ciências da Saúde (LIL ACS) e M edical L iterature A nal ysis and R etrieval System 0 nline (M E D LIN E), usando-se como descritores vulnerabilidade, mulher e Aids. Foram analisados 18 textos incluindo artigos em periódicos, teses e dissertações. Concluiu-se que mulheres idosas e vulnerabilidade à Aids estão diretamente relacionadas, através de características de gênero que perpassam pela submissão, construídas histórica e socialmente. É fundamental o desenvolvimento de estudos que gerem publicações acessíveis às mulheres, de modo a possibilitar que estas possam ver a si mesmas como sujeitos em risco de contrair Aids pelo simples fato de serem mulheres.

D escritores: Vulnerabilidade. Saúde da mulher. Síndrome de I munodeficiência A dquirida. I dentidade de gênero.

\section{RESUMEN}

E ste trabajo es una revisión sistemática de literatura que incluyó el período de 1994 a 2009, cuyo objetivo fue discutir la vulnerabilidad de la mujer anciana con respecto a Síndrome de la I nmunodeficiencia A dquirido (Sida). L a búsqueda por los textos científicos fue cumplida en las bases de la Biblioteca Virtual em Saúde, Scientific E letronic L ibrary Online (SciE L O), L iteratura L atino-A mericana e do Caribe em Ciências da Saúde (L IL A CS) y M edical L iterature A nalysis and R etrieval System Online (M E D LIN E), usando los descriptores vulnerabilidad, mujer y Sida. Se analizaron 18 textos incluyendo artículos en periódicos científicos, tesis y disertaciones. Se concluye que mujeres ancianas y vulnerabilidad al Sida están directamente relacionadas por características de género incluyéndose la sumisión y que se construyeron histórica y socialmente Consideramos como fundamental el desar rollo de estudios que puedan generar publicaciones accesibles a estas mujeres para ayudarlas a verse a sí mismas como personas en riesgo de adquirir el Sida por la simple condición de ser mujeres.

Descriptores: Vulnerabilidad. Salud de la mujer. Síndrome de Inmunodeficiencia Adquirida. I dentidad de género. T ítulo: $L$ a vulnerabilidad de mujeres ancianas con relación al Sida.

\section{ABST RACT}

This article is a systhematic literature review including the period from 1994 to 2009, whose objective was to discuss theaged woman's vulnerability in relation to A cqui red I munodeficiency Syndrome(A ids). T he search for scientifictexts was accomplished in the foll owing databases: B iblioteca Virtual em Saúde, S cientific E letronic L ibrar y 0 nline (SciE L O ), L iteratura L atinoA mericana e do Caribe em Ciências da Saúde (L IL ACS) and M edical L iterature Analysis and R etrieval System Online (M E D L IN E ). T hedescriptors used w erevul nerability, woman and Aids. E ighteen tex ts w ereanal yz ed, including articles in scientific journals, thesis and disser tations. As a conclusion, it was noted that aged women and vulnerability to Aids are directly related, through gender characteristics including submission and that were built historical and socially. We consider as fundamental the development of studies which may generate publications accessible to women, in order to help them see themselves as persons vul nerable to A ids contagion just for being women.

D escriptors: Vulnerability. W omen's health. A cquired Immunodeficiency Syndrome $G$ ender identity.

$T$ itle: A ged w oman's vul nerability related to A ID S.

\footnotetext{
${ }^{a}$ M estre em E nfermagem, D outoranda do Programa de Pós-G raduação em E nfer magem da F aculdade de E nfer magem da U niver sidade do Estado do Rio de Janeiro (UERJ), Rio de Janeiro, Brasil.

b M estre em Enfermagem pela Faculdade de Enfermagem da UERJ, Rio de Janeiro, Brasil.

'D outor em Enfermagem, Pesquisador do Consel ho Nacional de D esenvolvimento Científico e T ecnológico (CN Pq), Professor T itular da Faculdade de Enfermagem da UERJ, Rio de Janeiro, Brasil.
} 


\section{INT RODUÇÃO}

Os dados epidemiológicos do Programa Conjunto das $\mathrm{N}$ ações U nidas sobre HIV e Aids (U naids) em dezembro de 2007, apontam que havia 33,2 miIhões de pessoas vivendo com a Síndrome da Imunodeficiência A dquirida (Aids) em todo o mundo, destes 15,4 milhões eram mulheres ${ }^{(1)}$. $\mathrm{Na}$ avaliação da tendência da pandemia observaram-se algumas características: existe uma epidemia concentrada em muitos Países da África; e epidemias no resto do mundo que se concentram principalmente entre as populações mais vulneráveis. D entre estes grupos destacam-se as mulheres infectadas por seus parceiros ${ }^{(1)}$.

Dados epidemiológicos indicam que vive no Brasil um terço de toda a população da América Latina infectada pelo vírus. Conforme dados do M inistério da Saúde ${ }^{(2)}$, o aumento do número de casos entre os heterossexuais trouxe consigo uma expressiva inserção das mulheres no quadro epidemiológico, ou seja, a epidemia experimenta os processos de feminização e heterossexualização da doença.

As mulheres, em função de sua trajetória histórico-social, têm se mostrado especialmente vulneráveis às doenças sexualmente transmissíveis, com destaque para a infecção pelo vírus da imunodeficiência humana (HIV). 0 contexto em que isto acontece geralmente envolve a dificuldade em negociar o uso do preservativo, a idéia de imunidade por viver um relacionamento estável complementada pela crença no amor romântico e protetor presente nessas relações ${ }^{(3)}$.

É marcante ainda a submissão feminina conseqüência das relações assimétricas de gênero e poder. H istoricamente oprimida, subjugada, a muIher tem tido poder bastante limitado no campo das relações afetivo-sexuais. Por isso mesmo, consciente ou inconscientemente, em algum momento do relacionamento, optam por submeterem-se às escolhas do parceiro ${ }^{(3)}$.

Grande parte dessas mulheres se contamina, em plena idade reprodutiva. N o entanto, observase um aumento crescente de casos entre adultos acima dos 50 anos $^{(1)}$. A ssim, o objetivo deste estudo foi discutir a vulnerabilidade da mulher idosa em relação às D oenças Sexualmente T ransmissíveis/ Aids (DST / A ids).

\section{METODOLOGIA}

0 presente texto consiste de revisão sistemática de liter atura $a^{(4)}$, abrangendo o período de 1990 a 2009. A escolha da década de 1990 como marco inicial deveu-se ao fato ter sido nesta época verificado 0 aumento do número de mulheres infectadas pelo HIV ${ }^{(5)}$.

Foi realizada a busca de textos científicos incluindo artigos em periódicos, teses e disser tações, nas bases da Biblioteca Virtual em Saúde (BVS), Scientific E letronic L ibrary O nline (SciE Io), Literatura Latino-A mericana e do Caribe em Ciências da Saúde (LILACS) e M edical L iterature Analysis and Retrieval System Online (MEDLINE). A busca foi realizada utilizando os descritores vulnerabilidade, mulher e Aids, constantes da relação de Descritores em Ciências da Saúde na Biblioteca Virtual em Saúde. Os critérios de inclusão dos textos foram: textos completos disponibilizados; abordagem da temática da vulnerabilidade da muIher à doença, da transmissão heterossexual e da transmissão por via sexual.

A busca bibliográfica realizou-se em três etapas para identificação e seleção dos textos: inicialmente foi feita a partir da combinação dos descritores vulnerabilidade e Aids para 0 que foram encontrados 100 títulos; em seguida usou-se a combinação dos descritores vulnerabilidade e mulher para a qual foram encontrados 36 títulos, que se repetiam com a combinação anterior; por fim utilizou-se a combinação dos três descritores com a qual foram identificados os 18 títulos, também identificados nas combinações anteriores de descritores, e que integraram o corpo de análise.

Os estudos que abordavam a vulnerabilidade de homossexuais ou usuários de drogas foram excluídos. Assim, foram selecionados no total 18 títulos ${ }^{(1,3,5-20)}$, que disponibilizavam texto completo, entre teses, dissertações e artigos em periódicos, que integraram o corpo de análise.

0 processo de análise se deu em etapas: a construção do protocolo; a definição da pergunta norteadora do estudo; a busca dos estudos; a seleção dos estudos; a aval iação crítica dos estudos; e a síntese dos dados, nos permitindo a identificação de cinco eixos temáticos norteadores de nossa discussão(4). Para nortear este estudo procuramos responder à seguinte questão: como tem se configu- 
rado, no contexto da epidemia do HIV/Aids no Brasil, a vulnerabilidade de mulheres idosas em relação às doenças de transmissão sexual, em especial ao HIV/ Aids? A partir de então procedeuse a identificação e seleção dos textos de acordo com os critérios de inclusão; leitura dos mesmos identificando o(s) núcleo(s) temático(s) abordado(s).

\section{RESULTADOS E DISCUSSÃO}

A análise dos textos permitiu a identificação de cinco grupos temáticos norteadores de nossa discussão: A trajetória histórica da mulher e sua vulnerabilidade para as DST / AIDS, 0 HIV/ Aids como doença do outro, A desigualdade de gênero como fator de vulnerabilidade, A dependência afetiva, a carência, o romantismo e a submissão feminina, como fatores de vulnerabilidade e, por fim, A relação entre a informação sobre a doença e a baixa consciência do uso do preservativo. Estes núcleos temáticos emergiram de nossa interpretação dos assuntos abordados nos textos estudados, onde a questão de gênero e a idéia de vulnerabilidade individual apareceram com destaque.

\section{A trajetória histórica da mulher e sua vulnerabilidade para as DST / Aids}

$\mathrm{H}$ istoricamente, as mulheres até o final da década de 80, ainda não haviam sido destacadas no contexto da expansão da epidemia. A Aids era uma doença pertencente a certos grupos de risco como os homossexuais masculinos, de usuários de drogas injetáveis, dos hemofílicos/transfundidos e, no máximo de suas parceiras sexuais( ${ }^{(6)}$.

A crença de que o HIV e a Aids fossem restritos a grupos especiais, aparentemente bem definidos e freqüentemente marginalizados, reforçou estereótipos e preconceitos sobre identidade sexual e sexo imoral, em vez de destacar o que há de comum em todos os comportamentos sexuais ${ }^{(7)}$. Várias relações e comportamentos sexuais não são admitidos e, dessa forma, os riscos da transmissão do HIV via práticas heterossexuais têm sido negados. M uito tempo se levou para identificar fatores sociais, econômicos e biológicos que estão presentes na transmissão do vírus e muito ainda não se sabe.

$\mathrm{N}$ a década de 1990 até os dias atuais, 0 alto contingente de mulheres com Aids, foi destacado pela mídia. No entanto, a maioria dos programas educativos se direcionava apenas para as mulheres profissionais do sexo e as gestantes devido ao risco de transmissão para o bebê( ${ }^{(5)}$. Excluíam-se assim as mulheres que não se enquadravam em tais características, dentre as quais as idosas.

Quando pensamos em mulheres idosas percebe-se que a sociedade determina quem deve ter ou não ter atividade sexual, de acordo com sua idade cronológica. A credita-se que estas mulheres que já tem um papel social de esposa bem definido, mesmo que já infectadas pelo vírus, não se identificam com os chamados grupos vulneráveis e a Aids continua a ser pensada como uma doença do outro.

\section{O HIV/ Aids como doença do outro}

Esta idéia de doença do outro e não de todos se fundamentam em raízes históricas geradas pela pandemia HIV/Aids. A idéia inicial de grupos de risco e posteriormente comportamento de risco, apontavam para grupos específicos que eram condenados pela sociedade por terem hábitos considerados inadequados. A pesar de nos dias atuais 0 HIV/Aids ser uma doença de todos, permanece ainda esta idéia de que a doença só atinge a determinados grupos. D entre estes, destacam-se as profissionais do sexo.

É percebido um sistema classificatório, que relaciona os limites de quem pode ou não pegar Aids, de um lado mulheres promíscuas, com comportamentos não aceitos pela sociedade e por outro as mulheres com somente um parceiro, onde a afetividade e 0 amor estão presentes ${ }^{(5)}$. Assim existe a idéia de que Aids é doença de mulher promíscua, que faz com que o pensamento hegemônico sobre mulher/ Aids promova "uma mistura contraditória de excesso e falta de visibilidade, em detrimento das próprias mulheres"(3), já que para muitas mulheres o único comportamento de risco seria fazer sexo sem camisinha com seu marido. Reafirma-se assim a idéia de que mulheres profissionais do sexo são as que têm e transmitem doenças e as com união estável são as aceitas pela sociedade por não apresentar riscos.

Por outro lado, enquanto em alguns estudos, ter relação com mulher profissional do sexo é certo 0 uso do preservativo, em outros, a negociação por sexo seguro é reduzido, em virtude da relação de poder do cliente. A profissional do sexo passa a ser vista como uma mercadoria que se deve adequar às exigências do consumidor, ficando mais vulneráveis a Aids ${ }^{(5)}$. 
D esta forma, entende-se que, homens que mantêm relações sexuais extraconjugais desprotegidas com profissional do sexo ou não, submetem suas parceiras a um maior risco, pois a idéia da mulher que possui uma união estável e fiel ter Aids ainda não é aceita pela sociedade.

Esta afirmação é confirmada em outro estudo, onde o outro aparece como mais vulnerável a adquirir a doença e as mulheres entrevistadas, se percebem supostamente protegidas. Para os autores, as mulheres entrevistadas acreditavam que a doença estava ligada a comportamentos que justificavam a contaminação. A idéia de imunidade, também se apresenta, quando se refere que as muIheres casadas devem ter uma menor preocupação em relação às DST / Aids(3).

Esta idéia do outro adquirir Aids, também se observa entre os idosos, quando nos deparamos com um estudo, que relata que dos participantes, 33\% não referenciavam fatores de risco para contrair Aids(3). Quando pensamos em mulheres idosas, esta idéia do outro adquirir Aids é muito mais presente, pois somados aos fatores apresentados anteriormente, acrescenta-se em outro estudo, concepções errôneas sobre a sexualidade na terceira idade são evidenciadas. D entre essas concepções errôneas destaca-se a idéia do idoso como sendo assexuado o que, consider ando a situação das mulheres idosas, as torna ainda mais vulneráveis às DST / Aids ${ }^{(8)}$.

É perceptível que esta idéia de idoso assexuado, ainda é mantida socialmente porque até recentemente ainda se acreditava que por volta desta idade, ocorria um declínio da função sexual intenso e inevitável devido à menopausa feminina e à instalação progressiva das disfunções da ereção masculina. D esta forma, atividades de prevenção esta população se tornam deficientes.

Contraditoriamente, as idosas correm os mesmo riscos de contrair Aids quando comparados a outras pessoas de outras faixas etárias, pois também estão envolvidos em atividades sexuais. Esta afirmação é confirmada em pesquisa segundo a qual $39 \%$ das pessoas com mais de 60 anos mantém relações sexuais com regularidade ${ }^{(8)}$.

I números são os aspectos que interferem na vulnerabilidade à Aids, dentre estes, a identidade sexual e de gênero estão em destaque ${ }^{(9)}$. Assim 0 aumento da vulnerabilidade da mulher frente ao HIV/Aids é característico no padrão de contaminação de todo o mundo e a discussão no cam- po que nos remete as questões de gênero se torna essencial para o entendimento de como, ao longo dos anos, se deu o incremento da participação feminina nos números da epidemia.

\section{A desigualdade de gênero como fator de vulnerabilidade}

A idéia de gênero, pode ser considerado um obstáculo para a percepção da vulnerabilidade à infecção ou a reinfecção pelo HIV ${ }^{(9)}$. A desigualdade entre os sexos, é fruto de um processo histórico que revela uma submissão da mulher em relação ao homem. As mulheres eram desviadas do poder de decisão na vida pública ou privadas e a violência cotidiana, doméstica e sexual fazia parte da sua realidade. As mulheres têm menor liberdade em sua vida sexual e têm menos poder de decisão acerca do sexo com proteção. D esta forma, estas relações desiguais se traduzem em uma maior vulnerabilidade para as mulheres, contribuindo para o aumento dos números na pandemia ${ }^{(9)}$.

Com relação às mulheres que convivem com algum tipo de violência, quando influenciada por questões de gênero, pesquisas apontam como um grupo altamente vulnerável ao HIV/Aids, tendo em vista a possibilidade de serem obrigadas a ter relações sexuais feitas de forma obrigatória e sem proteção. No Brasil, estudo feito com gestantes portadoras da doença demonstrou que a falta de negociação e a convivência com a violência doméstica levam a mulher a poucas opções de segurança contra a contaminação pelo vírus HIV gestantes portadoras do vírus HIV/ Aids ${ }^{(10)}$.

Quando pensamos na idéia de gênero relacionado ao envel hecimento, nos remete as intervenções farmacológicas, utilizado pelo homem idoso para exercer sua virilidade e a mulher idosa 0 papel de negar sua sexualidade, já que não se encontra mais na sua idade reprodutiva. Os representantes masculinos percebendo seu potencial sexual começam a se relacionar, quase sempre com mulheres mais jovens e atraentes, pois não há supostamente uma razão aparente de escolher uma mulher de sua idade, uma vez que imaginam encontrar esta desvalorizada sexualmente. Contraditoriamente a isso além de manter relações extraconjugais, possuem relações sexuais com sua parceira sem proteção, propiciando a um aumento da vulner abilidade a doença entre estas mulhe- 
res idosas. Sendo assim estes homens idosos, se vendo com menos oportunidades do que os mais jovens, recorrem aos serviços de prostituição, comprando sexo(11).

$\mathrm{N}$ o estudo feito com homens motoristas de ônibus e integrantes de uma Comissão I nterna de Prevenção de Acidentes (CIPA) em uma empresa de transportes coletivos na cidade de São Paulo, encontramos falas que refletem esta diferença de gênero. É permitido, segundo os entrevistados, que na fase adulta os homens tenham relações extraconjugais, se estiver longe da esposa. Contraditoriamente a isto, a mulher deve ser virgem e destinada para o casamento, mais especificamente, à procriação, não sendo então permitida mais nenhuma outra prática sexual além da vaginal, pois as demais são mantidas fora ${ }^{(12)}$. A infidelidade feminina é entendida como possível apenas quando falta alguma coisa que o companheiro não oferece e a masculina como algo natural, característico do homem.

E $m$ outro realizado com mulheres de Camaragibe, em 2005, observou-se que o casamento é 0 maior objetivo dessas mulheres, porque funciona como uma comprovação de mulher bem sucedida, que se excluem daquelas de rua. 0 sexo é visto como mais uma obrigação doméstica da mulher e um desejo do marido. Sendo o sexo uma necessidade do homem, as práticas extraconjugais são percebidas como fato natural, pois mesmo não sendo uma atitude desejada, tornando-se realidade será compreendida pela esposa. Por essas razões, não se confia no parceiro, mas também não há cobranças. Ou seja, estes possíveis relacionamentos extraconjugais do marido possivelmente sem proteção, as colocam mais vulneráveis a Aids ${ }^{(13)}$.

Quando associamos a percepção destas muIheres diante destas relações onde a questão de gênero está muito presente, a união estável aparece como fator de proteção. Esta idéia de imunidade, associada à dependência afetiva, à carência e ao romantismo as colocam muito mais vulneráveis a adquirir a doença.

\section{A dependência afetiva, a carência, 0 romantismo e a submissão feminina como fatores de vulnerabilidade}

Os relacionamentos humanos se sustentam em pilares que geram uma relação de dependência entre as pessoas envolvidas, devido à troca de sen- timentos contidos nas relações. Diante disso, destacam-se alguns estudos onde estes fatores foram apontados como predisponentes a não negociação por sexo seguro.

0 casamento é destacado pelas mulheres como fator de proteção à doença. 0 casar para as muIheres representa amor, fidelidade, respeito, confiança e cumplicidade. Há um pressuposto de que, ao assumir tais valores na vida cotidiana, homens e mulheres estariam protegidos do risco de se infectarem. 0 casamento gera uma visão romântica e eter nizada do amor entre 0 casal e isto pode fazer com que se abandone a utilização de preservativos e acredite estarem realmente protegidos contra a Aids(3).

A credita-se que para as mulheres adolescentes a negociação por sexo seguro, associada à perda de virgindade e ao primeiro homem e amor, favorece a exposição ao vírus, através de relações sexuais não protegidas. No entanto, estudo realizado em Pelotas (RS) evidenciou que muitas mulheres consideram quase impossível contrair DST / A ids ${ }^{(14)}$.

Os jovens avaliam como sendo alto o risco representado pelo HIV/ Aids para pessoas de sua faixa etária, devido às especificidades que a própria idade os coloca. É perceptível que mais da metade dos participantes declararam pelo menos uma experiência sexual arriscada ${ }^{(15)}$.

Os dados do estudo sobre jovens do Vale de Kathmandu, $\mathrm{N}$ epal, também apontam para esta direção, foi analisado que eles, principalmente as meninas são altamente vulneráveis a doenças devido ao uso irregular do preservativo, por terem um único parceiro ${ }^{(16)}$.

Os idosos vêem o HIV/ Aids, como algo também presente entre os mais jovens ${ }^{(17)}$. No entanto, os autores acreditam que para as mulheres idosas a não negociação por sexo seguro é muito mais presente quando pensamos em relações mais duradouras onde o companheirismo e a necessidade do outro é mais evidenciada.

Segundo mulheres entrevistadas em um estudo, sugerir a utilização do preservativo, que não por contracepção, pode provocar a desconfiança do parceiro de estar sendo traído ou de se sentir desacreditado pela esposa em suas atitudes extraconjugais. T ambém foi comum elas afirmarem que os homens não gostam, que é incômodo e que se só tem a elas, não é necessário a prevenção contra doenças ${ }^{(3)}$. 
A credita-se que esta última afirmação nos remete a mais uma demonstração do poder masculino exercido sobre mulher, já que uma das questões mais importantes no contexto atual é a falta da negociação do uso do preservativo pela mulher, pelo fato deste método ser controlado pelos homens. $\mathrm{E}$ estes sendo os dominantes da relação colocam as mulheres em posição de subordinação afetiva.

Ratificando a afirmação acima, em um estudo feito em 2007, com gestantes infectadas pelo vírus, demonstrou que antes delas se infectarem, al gumas entrevistadas já eram cientes ou suspeitavam que o seu parceiro era soropositivo para o HIV. M esmo assim, eram mantidas relações sexuais com eles e em nenhum momento era questionado ao menos 0 uso de preservativo feminino. E mbora fossem cientes desta informação, talvez pela baixa auto-estima, por medo de solidão não exigiam seu uso ${ }^{(10,18)}$.

A idéia de submissão é resultante das diferenças de poder entre homens e mulheres ${ }^{(3)}$. Em um estudo realizado com mulheres da região de Camaragibe, foi descrito que estas mulheres são criadas desde sua infância baseadas na firmação de poder masculino, a submissão e o dever de ser boa mãe e esposa as colocam vulneráveis, quando se relaciona a aceitação de valores considerados normais do homem. Ainda neste estudo todas as vezes que o tema camisinha foi abordado entre as mulheres, o preservativo surgia como método contraceptivo, nunca como barreira de doenças ${ }^{(13)}$. E stes fatores são bem evidenciados quando pensamos em idosas, pois a visão de que uma relação de muito tempo é monogâmica, eliminaria a possibilidade de 0 parceiro ter atividades sexuais desprotegidos com outra pessoa ${ }^{(8)}$. D esta forma, a dependência afetiva, a submissão e o medo de ficar sozinha propiciam a vulnerabilidade de mulheres jovens ou não quando o exigir o uso do preservativo pode significar a perda do parceiro(3).

Percebe-se que o auto cuidado da saúde destas mulheres fica prejudicado. Pois se relaciona diretamente a consciência de si, da sua própria importância e valor, bem como depende do investimento que cada mulher está disposta a fazer em si mesma ${ }^{(19)}$

Os autores acreditam que para que a mulher se cuide, fazendo a opção por sexo seguro é necessário o conhecimento dos métodos de prevenção da doença, pois a falta de informação as coloca mais vulneráveis a doença.

\section{A relação entre a informação sobre a doença e a baixa consciência do uso do preservativo}

0 desconhecimento sobre vias de transmissão e as formas de prevenção foram achados importantes em um estudo, apontadas pelas mulheres entrevistadas como fatores mais importantes para adquirir a infecção ${ }^{(13)}$. Já com as idosas, a falta de informação e percepção de risco parecem estar evidenciados quando relatam que tem pouco conhecimento sobre Aids e não se vêem com risco de contrair a doença(3).

No entanto, uma vez que o conhecimento sobre a transmissão da Aids parece ser excelente, muitos indivíduos não têm comportamentos voltados para a redução do risco de contrair a doença, como sexo seguro(13). A baixa consciência sobre sua vulnerabilidade durante a relação sexual não se deve apenas à desinformação ${ }^{(9)}$. A falta de informação figura entre as diversas conseqüências do ester eótipo feminino extensamente relatado na literatura, no qual a mulher tem que ser ingênua e passiva $^{(3)}$

As mulheres atribuíram pouco valor ao preservativo devido ao argumento de que impedia o prazer e ou que preservativo poderia romper-se durante a relação sexual ou o medo de prurido e queimação(9). Percebe-se que 0 fato das mulheres terem informações ou se acharem susceptíveis ao HIV, não justifica a negociação da proteção em suas relações sexuais(10). Sendo assim, é fato que enquanto as mulheres não se sentirem no direito ou encontrarem a sua maneira de agir como sujeitos sexuais, elas continuaram a deparar-se, por exemplo, com a dificuldade de convencerem seus parceiros quanto ao uso do preservativo. Empoderar estas mulheres significa oportunizar a elas estratégias capazes de mudar suas vidas ${ }^{(20)}$.

\section{CONCLUSÕES}

Conclui-se que mulheres, independente de faixa etária, raça, profissão, grau de instrução e informação, estão diretamente vulneráveis a Aids principalmente em conseqüência de várias características dos contextos político, econômico e so- 
ciocultural. É nesse contexto que as relações assimétricas de gênero e poder tor nam as mulheres ainda mais vulneráveis.

$N$ estas circunstâncias as mulheres idosas aparecem com destaque no que se refere à vulnerabilidade para contrair HIV/Aids, dadas as características de seus relacionamentos afetivosexuais. Este grupo de mulheres atribui a vulnerabilidade aos jovens, demonstrando baixa percepção de risco, não vendo a si mesmas também muito vulneráveis.

A ssim compreende-se que é fundamental que as mulheres, principalmente as idosas, tenham uma percepção de si como de indivíduos em risco e que se identifiquem nas informações sobre prevenção da Aids. Esta se configura como condição básica para mudança de atitude e comportamento em relação à própria proteção.

\section{REFERÊNCIAS}

1 Programa Conjunto de las $\mathrm{N}$ aciones U nidas sobre el VIH/Sida; Organización M undial de la Salud. A mérica Latina: situación de la epidemia de sida: resumen regional [ Internet] . G inebra; 2008 [ citado 2008 jun 13] . Disponible en: http:/ / data.unaids.org/ pub/ Report/ 2008/ jc1530_epibriefs_latinamerica_ es.pdf.

2 Vermelho LL, Barbosa RHS, N ogueira SA. M ulheres com Aids: desvendando histórias de risco. Cad Saúde Pública [ Internet] . 1999 [ citado 2010 ago 16] ;15(2): 369-79. Disponível em: http:/ / www.sciel osp.org/ pdf/ csp/ v15n2/ 0321.pdf.

3 Silva CM , Vargens O M C. A percepção de mulheres quanto à vulnerabilidade feminina para contrair DST / HIV. Rev Esc Enferm USP. 2009;43(2):401-6.

4 H olopainen A, Hakulinen-Viitanen T, Tossavainen $\mathrm{K}$. Systematic review: a method for nursing research. N urse Res. 2008;16(1):72-83.

5 Espósito APG, Kahhale E M P. Profissionais do sexo: sentidos produzidos no cotidiano de trabalho e aspectos relacionados ao HIV. Psicol Reflex Crít. 2006; 19(2):329-39.

6 G iami A. Representações da AID S: uma teoria sexual da AIDS. Rev Enferm UERJ. 2006;14(1):113-21.

7 Berer M. M ulheres e HIV/ AIDS: um livro sobre recursos internacionais. São Paulo: Brasiliense; 1997.
8 Lieberman R. HIV in older A mericans: an epidemiologic perspective.J M idwifery W omens H ealth. 2000; 45(2):176-82.

9 Sal danha AAW. Vulnerabilidade e construçoes de enfrentamento da soropositividade ao HIV por muIheres infectadas em relacionamento estável [ tese] . São Paulo: F aculdade de F ilosofia, Ciências e Letras de Ribeirão Preto, U niversidade de São Paulo; 2005.

10 Cechim PL, Perdomini FRI. Gestantes HIV positivas e sua não adesão à profilaxia no pré-natal. Rev Bras Enferm. 2007;60(5):519-23.

11 Silva LS, Paiva M S. Vulnerabilidade ao HIV / Aids entre homens e mulheres com mais de 50 anos. In: A nais do 70 HIV-AIDS Virtual Congress; 2006 out 10; L isboa, Portugal [ Internet] . Lisboa: AI D S Portugal; 2006 [ citado 2010 ago 15]. Disponível em: http:/ / www.aidscongress.net/ html/ comunicacaoa 243.html?num=308.

12 Guerreiro I, Ayres J RCM , H east N . M asculinidade e vulner abilidade ao HIV de homens heterossexuais. Rev Saúde Pública. 2002;36(4):50-60.

13 N ascimento A M G, Barbosa CS, M edrado B. M ulheres em Camaragibe: representação social sobre a vulnerabilidade feminina em tempos de Aids. Rev Bras Saúde M ater I nfant. 2005;5(1):1-15.

14 Silveira M F, Béria JU, H orta BL, Tomasi E. Autopercepção de vulnerabilidade às doenças sexualmentetransmissíveis eA ids em mulheres. Rev Saúde Pública. 2002;36(6):670-7.

15 Vieira EM, Villela $W V$, Réa M F, Fernandes $M E L$, Franco $E$, Ribeiro $G$. Alguns aspectos do comportamento sexual e prática de sexo seguro em homens de M unicípio de São Paulo. Cad Saúde Pública. 2000; 16(4):997-1009.

16 Puri M, Cleland J. Sexual behavior and perceives risk of HIV among young migrant factory workers in Nepal. J Adolesc Health. 2006;38:23746.

17 Ory M G, M ack KA. M iddle aged and older people with A ids. Res Aging. 1998;20(6):653-64.

18 Preussler G M I, E idt OR. Vivenciando as adver sidades do binômio gestação e HIV / AIDS. Rev G aúcha Enferm. 2007;28(1):117-25. 
19 M aliska ICA, Souza M IC, Silva D M G V. Práticas sexuais e 0 uso do preservativo entre mulheres com HIV/aids. Ciênc Cuid Saúde. 2007;6(4):4718.
20 M eneghel SN, Barbiani R, Steffen $H$, W under AP, Roza M, Roter mund J, et al. Impacto de grupos de mulheres em situação de vul nerabilidade de gênero. Cad Saúde Pública. 2003;19(4):955-63.
Endereço do autor / Dirección del autor / Author's address:

O ctavio M uniz da Costa Vargens

Rua Constante Ramos, 136, ap. 503

22051-012, Rio de Janeiro, RJ

E-mail: omcvargens@uol.com.br
Recebido em: 19/ 01/ 2010

A provado em: 23/ 07/ 2010 